\title{
Detection of Helicobacter pylori associated antigen and heat shock protein 60 on follicular dendritic cells in the germinal centres of low grade B cell lymphoma of gastric mucosa associated lymphoid tissue (MALT)
}

Keita Kobayashi, Kenji Yokota, Tadashi Yoshino, Yoshiro Kawahara, Ashoka Dey, Yoshikazu Hirai, Keiji Oguma, Tadaatsu Akagi

\begin{abstract}
Aims-To investigate the localisation of Helicobacter pylori antigens and the expression of human heat shock proteins (HSP) in stomachs affected by MALT lymphoma.

Methods-Surgically resected stomachs from 24 patients with MALT lymphoma were immunostained with anti-H pylori rabbit antibodies (ORP-1 and ORP-2) and anti-human HSP60 mouse monoclonal antibodies (mAb) (LK-1 and LK-2).

Results-Follicular dendritic cells of germinal centres in the stomachs affected by MALT lymphoma were immunostained with anti-H pylori polyclonal antibodies and with anti-human HSP60 $\mathrm{mAb}$, as were the epithelial cells. None of the lymph node samples reacted.

Conclusions-Human HSP60, which cross reacts with anti-H pylori polyclonal antibodies, is often expressed on follicular dendritic cells in gastric MALT lymphoma tissues and may be aetiologically relevant to lymphomagenesis of MALT lymphoma.

(F Clin Pathol 1998;51:396-398)
\end{abstract}

Keywords: Helicobacter pylori; immunohistochemistry; MALT lymphoma

Okayama University

Medical School,

Okayama, Japan

Department of

Pathology

K Kobayashi

T Yoshino

A Dey

T Akagi

Department of

Microbiology

K Yokota

Y Hirai

K Oguma

Department of Internal Medicine

Y Kawahara

Correspondence to:

Professor T Akagi,

Department of Pathology,

Okayama University Medica

School, Shikata-cho 2-5-1,

Okayama 700, Japan.

Accepted for publication 4 March 1998 reinfection ${ }^{8}{ }^{9}$ have been reported. The presence of clonal IgH gene rearrangements ${ }^{10}$ and the substantial number of lymphocytes and plasma cells with the immunoglobulin idiotype of MALT lymphoma ${ }^{11}$ in chronic gastritis associated with $H$ pylori also support the hypothesis that $H$ pylori is involved in the pathogenesis of low grade gastric MALT lymphomas. In this report, we describe the pathogenic implications of heat shock protein (HSP) from $H$ pylori and humans in the development of gastric low grade MALT lymphoma.

\section{Methods}

TISSUES

The stomachs were surgically resected from 24 patients with gastric low grade MALT

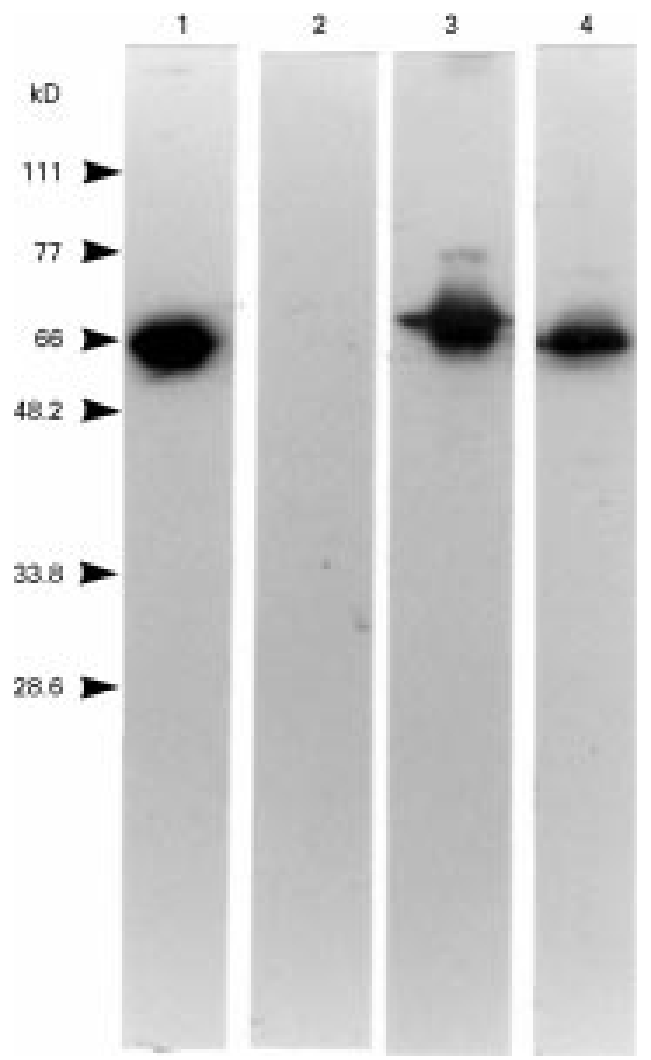

Figure 1 Western blotting analysis of the reactivity of anti-human HSP60 monoclonal antibodies (LK-1, lanes 1 and 2; LK-2, lanes 3 and 4) with human HSP6O (lanes 1 and 3) and the extract of H pylori (lanes 2 and 4). LK-2 cross reacts with a protein of about $66 \mathrm{kDa}$ in $\mathrm{H}$ pylori extract, probably corresponding to HSP60 of H pylori. 

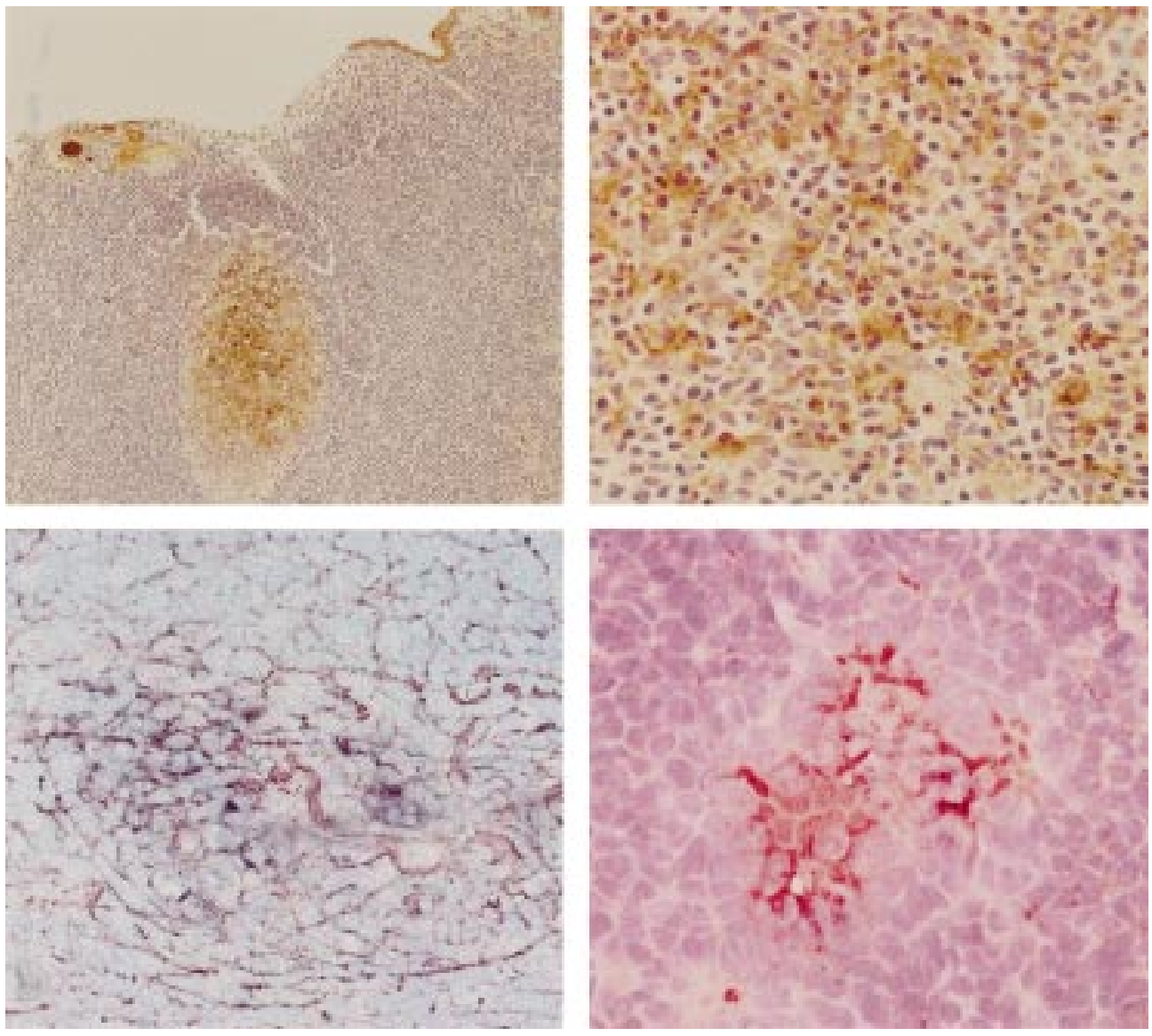

Figure 2 Immunohistochemical staining of gastric lymphoid tissue of MALT lymphoma with a rabbit anti-H pylori antibody (ORP-1) and an anti-human HSP60 monoclonal antibody (LK-2). Top left: The reactive germinal centre and some epithelial cells are positively immunostained $(O R P-1, \times 72)$. Top right: Immunoreaction products are localised on follicular dendritic cells in the germinal centre showing colonisation (ORP-1, $\times 290)$. Bottom left: Double immunostaining for follicular dendritic cells (CD35) and H pylori antigen (ORP-1). Follicular dendritic cells, red; $H$ pylori antigen, blue (×290). Bottom right: Immunostaining for human HSP60. Frozen section (LK-2, magnification $\times 290)$.

lymphoma and from five patients with gastric ulcer infected with $H$ pylori. Formalin fixed, paraffin embedded specimens were obtained from all of the patients. Frozen sections were available from three cases of MALT lymphoma. Lymph node samples from patients with gastric MALT lymphoma (five cases), colon cancer (seven cases), prostatic cancer (two cases), lung cancer (three cases), necrotising lymphadenitis (two cases), abscess forming granulomatous lymphadenitis (three cases), and reactive lymphadenitis (two cases) were also used.

\section{ANTIBODIES}

Anti- $H$ pylori polyclonal antibodies were raised in rabbits by immunising them with sonicated whole cells of $H$ pylori intravenously and subcutaneously. Purified IgG antibodies (ORP-1 and ORP-2) were obtained from the pooled sera and used at a dilution of 1:100. Peroxidase conjugated and non-conjugated rabbit antibodies against human $\operatorname{Ig} \gamma$ chain, $\operatorname{Ig} \alpha$ chain, and $\operatorname{Ig} \mu$ chain were purchased from Dako (Copenhagen, Denmark).

Mouse monoclonal antibodies (mAb) against the human HSP60 (LK-1 and LK-2) were obtained from Stress Gen (Victoria, British Columbia, Canada) and used at a dilution of $1: 100$. Western blotting analysis showed that
LK-2 also cross reacted with HSP60 of Escherichia coli (Gro EL) and $H$ pylori (fig 1 ).

IMMUNOSTAINING

$H$ pylori antigens were immunostained by the ordinary avidin-biotin complex (ABC) method using ORP-1 or ORP-2 as a primary antibody and horseradish peroxidase conjugated antirabbit IgG goat F(ab')2 (Zymed Lab Co, San Francisco, California, USA) as a secondary antibody. For the immunohistochemical detection of the human HSP60, acetone fixed frozen sections were also examined by the $\mathrm{ABC}$ method using LK-1 or LK-2 as a primary antibody and peroxidase conjugated rabbit antimouse Ig (Dako) as a secondary antibody. Follicular dendritic cells were detected by antiCD35 mouse $\mathrm{mAb}$ and a catalysed signal amplification system (Dako). Alkaline phosphatase labelled secondary antibody was used for the double staining of HSP60.

\section{Results}

Paraffin embedded tissue sections from the stomachs affected by low grade MALT lymphoma were immunostained with the rabbit anti- $H$ pylori antibodies ORP-1 and ORP-2. These antibodies reacted with bacteria themselves in 22 of the 24 cases. Furthermore, the reaction products were localised in the 
cytoplasm and the luminal surface of some foveolar and glandular epithelia, although the reactivity was variable among the cells (fig 2, top left). Interestingly, these antibodies also reacted with the non-neoplastic germinal centres in 14 of the 24 cases (fig 2, top left). Some of the follicles showing follicular colonisation, consisting of an excess of centrocytelike cells, also contained positive reaction products (fig 2, top right). The germinal centres of the resected stomachs in one of the five patients with an $H$ pylori infected gastric ulcer also reacted. Preimmune rabbit serum reacted with none of these samples. Immunohistochemical reactivity in the germinal centres showed the reticular networks which are thought to correspond to follicular dendritic cells. The immunoreactivity of follicular dendritic cells was also confirmed by the double immunostaining for CD35 and for $H$ pylori antigens (fig 2, bottom left). None of the lymph node samples obtained from the patients with MALT lymphoma and other inflammatory or neoplastic diseases reacted with ORP-1 or ORP-2. Anti-human HSP60 mAb (LK-1 and LK-2) reacted with GCs in two of the three patients with gastric MALT lymphoma from whom frozen sections were obtained, which were also immunostained with anti- $H$ pylori polyclonal antibodies (fig 2, bottom right). On the other hand, anti-human HSP60 mAb did not react with germinal centres in three cases of reactive lymphoid hyperplasia used as a control.

\section{Discussion}

In this study, we showed that the $H$ pylori related antigens are expressed in the germinal centres of gastric MALT lymphoma tissues. The staining pattern of the germinal centres strongly suggested that the antigen recognised with anti- $H$ pylori antibodies is present on follicular dendritic cells; this was confirmed by the double immunostaining with anti-CD35 $\mathrm{mAb}$ and anti-H pylori polyclonal antibodies. The positive selection of $B$ cells on the basis of their high affinity for the antigen takes place in the germinal centres, where the high affinity $\mathrm{B}$ cell mutants are primed to become effective antigen presenting cells and receive help from $\mathrm{T}$ cells in the context of an antigen specific, MHC restricted cognate interaction. ${ }^{3}$ MALT lymphomas are of memory B cell origin and are closely associated with $H$ pylori infection, ${ }^{5}$ which induces reactive follicles in the stomach. These results suggest that MALT lymphoma may be driven to proliferate by the $H$ pylori antigens on the follicular dendritic cells. However, the follicular dendritic cells of the germinal centres were immunostained not only with rabbit anti- $H$ pylori polyclonal antibodies, but also with the anti-human HSP60 mAb LK-1 and LK-2. A rabbit antiserum against $H$ pylori HSP60 has been shown to cross react with the human HSP60, ${ }^{12}$ and LK-1 recognises only the human HSP60. Therefore one of the antigens expressed on follicular dendritic cells may be the human HSP60 induced after $H$ pylori infection. However, $H$ pylori HSP60 and other $H$ pylori related antigens are also trapped on follicular dendritic cells. We found that polyclonal antibodies against $H$ pylori and anti-HSP $\mathrm{mAb}$ also reacted with gastric epithelial cells in addition to follicular dendritic cells, which is consistent with the findings of a previous report. ${ }^{1314}$

Both anti-idiotypic antibodies produced against MALT lymphoma cells and immunoglobulin secreted from lymphoma cells reacted with normal tissue components. ${ }^{15}$ The germlines of $\mathrm{VH}$ genes used by MALT lymphoma are frequently found in autoreactive antibodies. ${ }^{2}$ Autoantibodies are often detected in patients with $H$ pylori infected atrophic gastritis. ${ }^{16}$ We recently found that sera from about $80 \%$ of the patients with MALT lymphoma reacted with recombinant human HSP60 (in preparation). Our study suggests that one of the autoantigens recognised by MALT lymphoma cell immunoglobulin may be HSP60, which may be aetiologically relevant to lymphomagenesis of MALT lymphoma.

This work was supported in part by a grant-in-aid for scientific research from the Ministry of Education, Science, Sports and Culture of Japan.

1 Isaacson PG, Spencer J. Malignant lymphoma of mucosaassociated lymphoid tissue. Histopathology 1987;11:44562

2 Du M, Diss TC, Xu C, et al. Ongoing mutation in MALT lymphoma immunoglobulin gene suggests that antigen stimulation plays a role in the clonal expansion. Leukemia 1996;10:1190-7.

3 Liu YJ, Johnson GD, Gordon J, et al. Germinal centers in T cell dependent antibody responses. Immunol Today 1992; 13:17-21.

4 Genta RM, Hamner HW, Graham DY. Gastric lymphoid follicles in Helicobacter pylori infection: frequency, distribution, and response to triple therapy. Hum Pathol 1993;24:577-83.

5 Wotherspoon AC, Ortiz-Hidalgo C, Falzon MR, et al. Helicobacter pylori-associated gastritis and primary B-cell gastric lymphoma. Lancet 1991;338:1175-6.

6 Bayerdörffer E, Neubauer A, Rudorph B, et al. Regression of primary gastric lymphoma of mucosa-associated lymphoid tissue type after cure of Helicobacter pylori infection. Lancet 1995;345:1591-4.

7 Wotherspoon AC, Doglioni C, Diss TC, et al. Regression of primary low grade B-cell gastric lymphoma of mucosabacter pylori. Lancet 1993;342:575-7.

8 Horstmann M, Erttmann R, Winkler K. Relapse of MALT lymphoma associated with Helicobacter pylori after lymphoma associated with Helicobacter pylc
antibiotic treatment. Lancet 1994;343:1098-9.

9 Cammarota G, Montalto M, Tursi A, et al. Helicobacter pylori reinfection and rapid relapse of low-grade B-cell gastric lymphoma. Lancet 1995;345:192

$10 \mathrm{Hsi}$ ED, Greenson JK, Singleton TP, et al. Detection of immunoglobulin heavy chain gene rearrangement by polymerase chain reaction in chronic active gastritis associated with Helicobacter pylori. Hum Pathol 1996;27:290-6.

1 Greiner A, Marx A, Heesemann J, et al. Idiotype identity in a MALT-type lymphoma and B cell in Helicobacter pylor associated chronic gastritis. Lab Invest 1994;70:572-8.

12 Macchia G, Massone A, Burroni D, et al. The HSP60 protein of Helicobacter pylori: structure and immune response in patient with gastroduodenal diseases. Mol Microbiol 1993;9:645-52.

13 Engstrand L, Scheynius A, Pahlson C. An increased number of $\mathrm{g} / \mathrm{d}$ T-cells and gastric epithelial cell expression of the groEL stress-protein homologue in Helicobacter pyloriassociated chronic gastritis of the antrum. Am $\mathcal{f}$ Gastroenterol 1991;86:976-80.

14 Negrini R, Lisato L, Zanella I, et al. Helicobacter pylori infection induces antibodies cross-reacting with human gastric mucosa. Gastroenterology 1991;101:437-45.

15 Hussell T, Isaacson PG, Crabtree JE, et al. Immunoglobulin specificity of low grade B cell gastrointestinal lymphoma of mucosa-associated lymphoid tissue (MALT) type. $A m \mathcal{F}$ Pathol 1993;142:285-92.

16 Neglini R, Savio A, Poiesi C, et al. Antigenic mimicry between Helicobacter pylori and gastric mucosa in the pathogenesis of body atrophic gastritis. Gastroenterology 1996;111:655-65. 